\title{
How Patients Experience and Give Meaning to Their Cancer-related Fatigue?
}

\section{A Qualitative Research in the Italian Context}

\author{
Serena Barello ${ }^{1}$, Guendalina Graffigna ${ }^{1}$, Giulia Lamiani ${ }^{2}$, Andrea Luciani ${ }^{3}$, Elena Vegni ${ }^{2}$, Emanuela Saita ${ }^{1}$, Karin \\ Olson $^{4}, \&$ Claudio A. Bosio \\ ${ }^{1}$ Faculty of Psychology, Università Cattolica del Sacro Cuore, Milan, Italy \\ ${ }^{2}$ Department of Health Sciences, San Paolo Teaching Hospital, Università degli Studi di Milano, Italy \\ ${ }^{3}$ Medical Oncology Unit, San Paolo Teaching Hospital, Università degli Studi di Milano, Italy \\ ${ }^{4}$ Faculty of Nursing, University of Alberta, Edmonton, Canada \\ Correspondence: Dr. Serena Barello, Faculty of Psychology, Università cattolica del Sacro Cuore, Largo Gemelli \\ 1, 20123, Milano, Italy. Tel: 39-2-7234-3863. E-mail: serena.barello@ unicatt.it
}

$\begin{array}{lc}\text { Received: January 14, } 2013 & \text { Accepted: January 29, } 2013 \quad \text { Available online: April 27, } 2013 \\ \text { doi:10.11114/ijsss.v1i2.44 } & \text { URL: http://dx.doi.org/10.11114/ijsss.v1i2.44 }\end{array}$

\begin{abstract}
Fatigue is a common experience occurring in $70 \%$ to $100 \%$ of advanced cancer patients with a great impact on quality of life and survival. Despite the complexity of this phenomenon, fatigue's psychosocial dimensions are still not well understood. The aim of this study was to deepen how Italian patients perceive and give meaning to their cancer-related fatigue through the analysis of their language. The study was designed using ethnoscience, an approach that allows to explore how meaning is conveyed through language. We interviewed 16 cancer patients with different level of fatigue ( 5 mild, 5 moderate, 6 severe). The data analysis showed that fatigue affected three experiential dimensions (mind, body and interpersonal relationships) which are characterized by different symptomatic manifestations depending on the level of fatigue. Patients' causal attributions also varied across levels of fatigue: patients with mild and moderate fatigue attributed their fatigue to psychological and contextual causes, whereas patients with severe fatigue attributed their fatigue to physical and medical causes. As fatigue affects multiple areas of patients' lives, this study suggests the importance of holistic treatments with a multidisciplinary approach able to support patient engagement and activation in their healthcare. This study also shows the importance of considering patients' causal attributions about fatigue, as these appeared to play a role in how patients managed fatigue. Finally, our data highlighted the importance of using a shared language when speaking with patients about fatigue as this may help patients to feel more understood and supported, thus also improving their quality of life and engagement in their care \& cure process.
\end{abstract}

Keywords: Cancer fatigue, Ethnoscience, psyco-oncology, patient engagement, qualitative research

\section{Introduction}

Feeling tired is a universal experience and a very common condition among people during their lives (David et al, 1990). Feeling tired is also a normal consequence of physical exercise, lack of sleep or intense mental efforts. However, although everyone can experience tiredness, it is generally resolved by resting or sleeping. Recent studies on patients affected by various diseases showed that fatigue, which constitutes a more severe form of tiredness, frequently occurs in neurological disorders, chronic obstructive pulmonary disease, eating disorders, AIDS, heart disease, endocrine or renal disease (Wolfe et al., 1996; Krupp et al., 1988; Solano et al., 2006). Studies focused on cancer patients have shown that in this clinical group the incidence of fatigue is higher than in any other group of patients (Forlenza et al., 2005). Seventy to $100 \%$ of cancer patients report suffering from fatigue (Olson et al., 2007; Donovan et al., 2012).

Cancer-related fatigue seems to be different from the experience of tiredness which is a normal part of daily life, and has been defined by patient as an unusual and persistent condition. Fatigue has usually been described as a 
subjective feeling of overwhelming tiredness, which is often unrelated to physical activity and interferes with daily functioning in patient's life (Mock et al., 2007; Broeckel et al., 1998).Cancer-related fatigue affects physical, cognitive, affective and behavioral domains and can be experienced at different levels that go from mild to severe (Aistars, 1987; Nail et al., 2002; Servaes et al., 2002; Olson et al., 2007). Detrimental effects to the patients are usually significant, with marked functional impairments (Buckvald et al., 1996), low level of social support (Shoofs et al., 2004) and poor quality of life (Rakib et al., 2005). This condition is not generally relieved by sleep or rest (Barsevick et al., 2008), and may be associated with declines in patients' quality of life as well as in their survival (Chow et al., 2008; Orre et al., 2011). Studies that explored the psycho-emotional components of cancer-related fatigue often used standardized and translated instruments, which were developed in countries other than the ones in which they were applied (Centeno et al., 2009); the hidden assumption which underlies these studies is that fatigue does not vary across social contexts and so it can be measured with the same tools everywhere. However, Glaus (1998) has noticed that the language used by patients to describe their fatigue varies across different social contexts. As language is the primary symbol system through which meaning is conveyed (Spradley, 1979), studying language variation across social contexts could be one way to examine the influence of the socio-cultural determinants on the meaning that patients attribute to their disease and on how they experience disease related symptoms. Understanding patient's perspective about their illness is particularly relevant both to plan and realize better targeted clinical interventions (Leventhal et al., 1997). Moreover, valuing patients' subjective illness experience is now more and more recognized as an effective way to foster patients' engagement in their care \& cure process thus making interventions more aligned to their unmet needs (Barello et al., 2012). This meaning-making process is strictly connected to the system of values and beliefs of the patients and usually finds its manifestation in their use of language (Kirshbaum et al., 2012). In this research field, a qualitative approach could be particularly suited to capture the nuances of individual experience in a more "ecological" perspective. Among qualitative methods, ethnoscience constitutes a suitable tool to explore socio-cultural phenomena through the study of language. Ethnoscience is based on the theoretical assumption that, as language is the primary human vehicle of meanings, there is a close connection between the linguistic expressions and the concrete human's experience (Graffigna et al. 2010). Specifically, language can be considered as a manifestation of underlying representations of reality and subjective experiences otherwise inaccessible. Thus, linguistic expressions can be considered as an object of research in order to discover the hidden phenomenical reality that language describes. Taking in consideration the linguistic expressions used by patients to describe their fatigue could provide a clearer understanding of how patients perceive their disease, and thus play an important role in shaping care and cure practices (Sakauye, 2002; Charles et al., 2006; Kaissi et al., 2004; Costantini et al., 2006; Di Mola et al., 2001; Surbone et al., 2004; Baider \& Surbone, 2010). The first qualitative study, which investigated fatigue through the use of ethnoscience, was conducted in Canada several years ago (Olson, 2007) and was aimed at identifying the specific features of fatigue in advanced cancer patients. The results of this research suggested that fatigue experience features five main perceived dimensions (changes in emotional, cognitive and muscular function; decreasing control over body processes and decreased social interaction) and highlighted the importance of considering the relationships between symptom clusters, speech patterns and the socio-cultural context within fatigue occurs.

In the present study, which is part of the Fatigue Study Project being conducted in five countries, we investigated how fatigue is experienced by patients in the Italian healthcare context. The aim of the study was to explore how Italian patients perceive and give meaning to their cancer related fatigue through the use of ethnoscience. In particular, the aims of this study was threefold: 1) to identify which areas of patients' lives are affected by fatigue; 2) to deepen how symptoms are experienced and described across different levels of fatigue; and 3) to explore how patients explain their fatigue experience through the analysis of the linguistic patterns they use to describe it.

\section{Methods}

A qualitative research design was used to grasp cancer patients' subjective and situated experiences of fatigue. Specifically, we chose ethnoscience because this approach is particularly suited to study subjective experience shared through language. Ethnoscience can be defined as the systematic study of people's perceptions, knowledge, and classification of the world as shown in their language (Leventhal et al., 1997).

Ethnoscience provides an analytic approach for examining the words that patients use to describe and to signify a specific human condition. It provides a pathway for creating a shared dictionary of words used to describe an experience. Further details on the features and the heuristic value of ethnoscience in healthcare research are discussed elsewhere (Graffigna et al., 2011). 


\subsection{Setting and Study Participants}

The study was designed and conducted as part of a partnership between the Università Cattolica del Sacro Cuore (Italy), the Università degli Studi di Milano (Italy) and the University of Alberta (Canada). Data collection took place at San Paolo Teaching Hospital, Milan, from March to June 2011.

Following the receipt of ethical clearance from San Paolo Hospital's Institutional Review Board, participants were recruited among adult Italian patients admitted to Medical Oncology Unit who were diagnosed with advanced solid cancers (stages III or IV) and were receiving active or palliative chemotherapy. Additional eligibility criteria included: normal cognitive status, able to describe his/her own illness experience, and able to read and write Italian. Patients meeting these criteria were invited to participate in the study by two researchers (SB, GL), who explained the study, answered any questions, and obtained written consent from those who agreed to participate. Once the informed consent was obtained, participants were assessed by using the Edmonton Symptom Assessment System (ESAS) (Bruera et al., 1991). This scale is a 10-point numeric rating scale on which participants are asked to rate their tiredness from 0 (no fatigue) to 10 (worst possible fatigue). ESAS was developed in the palliative care settings for use in daily symptoms assessment and considers the presence and the severity of nine symptoms common in cancer patients: pain, tiredness, nausea, depression, anxiety, drowsiness, appetite, well-being and shortness of breath and fatigue. According to other studies' procedure (Olson, 2007), we considered a score of 1-3 as an indicator of mild fatigue, a score of 4-6 as moderate fatigue and a score of 7-10 as severe fatigue.

The sample was purposive and patients were theoretically selected as the study progressed in order to reach data saturation (Richards \& Morse, 2007). The aim was to build a maximum variability sample (Moore et al., 2008) in order to obtain a wide range of experiences related to the phenomenon under consideration. Attention was paid to recruiting patients with different levels of fatigue. Participants were also selected for their ability to offer a deeper account on their fatigue experience.

\subsection{Data Collection and Analysis}

Ethnoscience features a continuous and direct involvement of patients in the research process and consists of four main steps (Graffigna et al., 2011): 1) a first unstructured interview with patients; 2) a second encounter in which patients are involved in a card-sort task; 3) a construction of a taxonomy for each participant aimed at describing how words, phrases and expressions linked to their fatigue are related to each other; 4) a creation of a general taxonomy which is based on all of the taxonomies from each participant and that shows common patterns of believes and values regarding fatigue. As typical of all qualitative methods, data were collected and analyzed concurrently (Richards \& Morse, 2007). The process of data collection and analysis, according to the ethnoscience method, is described below. Data collection began with unstructured interviews with each patient, which were conducted by two researchers (SB, GL) from January 2011 to June 2011. All researchers were experienced in qualitative methods and received specific training in ethnoscience.

During this first interview patients were asked to openly talk about how they were feeling (e.g. "How are you doing today?"). When comments about fatigue were made, patients were asked additional questions to explore their experience (e.g. "Could you tell me more about this?" or "Could you give me an example?"). Interviews lasted around 60' (range: $45^{\prime}$ to $70^{\prime}$ '). At the end of each interview, demographic information and disease characteristics were also collected. The interviews were transcribed and imported into NVivo, a software which was used to manage data. The transcripts were independently analyzed and coded by three researchers(SB, GG,GL) aiming at identifying key words, phrases and expressions used more frequently by participants to describe their experience of fatigue. In a joint meeting, the researchers discussed and reached an agreement on a list of words/phrases extracted from the interviews transcripts that patients used to describe the experience of fatigue. Where disagreement emerged, the researchers reached a consensus through discussion. This process resulted in a shared "dictionary"; these words/phrases were then printed into cards for the second phase of the research process: the cards sort task. This task was conducted during a second encounter with the same patients, a few days after their first interview. In this encounter, patients were asked to sort the words they considered key to their experience of fatigue and to organize them into piles according to whatever criteria they considered appropriate. Patients then named the piles with a label that summarized their meaning. By talking with patients about the labels they gave to each pile, the researchers were able to learn more about the implicit meanings linked to the patients' fatigue experience. The researchers kept track of each patient card sort process and then drafted a taxonomy in the form of a table showing the results of the card sorts. In a separate meeting among researchers, the taxonomies derived from the card-sort task were compared to identify common patterns in the descriptions of fatigue. Following this analytical step, the researchers built a taxonomy summarizing fatigue's 
meanings and experience shared by all involved patients. This general taxonomy was finally tested in a third encounter with a selection of patients (those who were more able to articulate their experience in the researchers' perspective), some days after the second one. The taxonomy was finally revised according to the patients' inputs.

\section{Results}

\subsection{Participant Characteristics}

Sixteen patients (10 females and 6 males) with different levels of fatigue ( 5 mild, 5 moderate, 6 severe) were recruited. None of the patients who were invited to participate refused to enter the study. Further demographic characteristics of the patients are reported in Table 1. Among the entire group of participants, 4 patients (1 female with severe fatigue and 3 males with mild, moderate and severe fatigue), were involved in the third encounter.

Table 1. Socio-demographic characteristics of patients

\begin{tabular}{|c|c|c|c|}
\hline CHARACTERISTIC & DESCRIPTION & PATIENTS & $N=16$ \\
\hline \multirow[t]{2}{*}{ Gender } & Male & 6 & \\
\hline & Female & 10 & \\
\hline Age & Average (Range) & $71(50-82)$ & \\
\hline \multirow[t]{4}{*}{ Marital status } & Single & 1 & \\
\hline & Married & 9 & \\
\hline & Divorced & 2 & \\
\hline & Widow/widower & 4 & \\
\hline \multirow[t]{3}{*}{ Education } & Primary school & 4 & \\
\hline & Middle School & 4 & \\
\hline & High School & 8 & \\
\hline \multirow[t]{3}{*}{ Number of children } & 0 & 2 & \\
\hline & 1 & 9 & \\
\hline & 2 & 5 & \\
\hline \multirow[t]{7}{*}{ Primary diagnosis } & Lung & 4 & \\
\hline & Breast & 4 & \\
\hline & Colon & 3 & \\
\hline & Rectum & 2 & \\
\hline & Stomach & 1 & \\
\hline & Bladder & 1 & \\
\hline & Liver & 1 & \\
\hline \multirow[t]{3}{*}{ Level of fatigue } & Mild & 5 & \\
\hline & Moderate & 5 & \\
\hline & Severe & 6 & \\
\hline \multirow[t]{2}{*}{ Cancer stage } & III & 6 & \\
\hline & IV & 10 & \\
\hline
\end{tabular}

According to the aims of the study, findings are clustered according to these themes: (1) areas of patients' lives affected by fatigue, (2) changes in patients' experiences based on the level of fatigue, (3) patients' explanations of their fatigue.

3.2 Areas of Patient's Lives Affected by Fatigue: Mind, Body and Interpersonal Relationships.

Our participants pointed out that their experience of fatigue affected three main experiential fields: "mind", "body" and "interpersonal relationships" (Figure 1). 


\begin{tabular}{|c|c|c|c|c|c|}
\hline \multicolumn{3}{|c|}{ DOMAINS } & \multicolumn{3}{|c|}{ LEVEL OF FATIGUE } \\
\hline AREAS & DIMENSIONS & SUBDIMENSIONS & MILD & MODERATE & SEVERE \\
\hline \multirow{3}{*}{ MIND } & $\begin{array}{l}\text { Neuro-cognitive } \\
\text { functions }\end{array}$ & Memory & $\begin{array}{l}\text { Slight lack of } \\
\text { memory }\end{array}$ & $\begin{array}{l}\text { More trouble in } \\
\text { remembering things }\end{array}$ & $\begin{array}{l}\text { Extreme difficulty in } \\
\text { storing and recalling } \\
\text { information }\end{array}$ \\
\hline & \multirow[t]{2}{*}{$\begin{array}{c}\text { Psychological } \\
\text { processes }\end{array}$} & $\begin{array}{l}\text { Interests and } \\
\text { motivation }\end{array}$ & $\begin{array}{l}\text { Laziness } \\
\text { Push themselves to } \\
\text { keep on the interests } \\
\text { they had in the past }\end{array}$ & $\begin{array}{l}\text { Listlessness } \\
\text { Lack of stimuli } \\
\text { boredom }\end{array}$ & $\begin{array}{c}\text { Total lack of } \\
\text { motivation and/or } \\
\text { interest in doing } \\
\text { activities } \\
\text { Lack of goals } \\
\end{array}$ \\
\hline & & Emotions & $\begin{array}{l}\text { A bit of anxiety } \\
\text { Irritability } \\
\text { Restlessness }\end{array}$ & $\begin{array}{l}\text { Alternation of } \\
\text { depressive and } \\
\text { anxious state }\end{array}$ & $\begin{array}{c}\text { Depression } \\
\text { Intense sadness }\end{array}$ \\
\hline \multirow{4}{*}{ BODY } & \multirow{2}{*}{$\begin{array}{l}\text { Basic physiological } \\
\text { functions }\end{array}$} & Sleep quality & Good sleep quality & $\begin{array}{l}\text { Slightly restless } \\
\text { Disturbed sleep }\end{array}$ & Restless sleep \\
\hline & & Hunger & $\begin{array}{c}\text { Normal stimulus of } \\
\text { hunger }\end{array}$ & $\begin{array}{l}\text { Less stimulus to eat } \\
\text { than in the past }\end{array}$ & $\begin{array}{c}\text { Hunger is absent or } \\
\text { really diminished }\end{array}$ \\
\hline & \multirow{2}{*}{ Body functionality } & Available energy & Temporary tiredness & $\begin{array}{c}\text { Need of a greater } \\
\text { level of energy to } \\
\text { cope with daily tasks }\end{array}$ & $\begin{array}{c}\text { Extreme difficulty in } \\
\text { doing daily activities } \\
\text { and great energetic } \\
\text { expense }\end{array}$ \\
\hline & & Muscles efficency & $\begin{array}{l}\text { Temporary muscle } \\
\text { tiredness } \\
\text { Movements become } \\
\text { slower }\end{array}$ & $\begin{array}{l}\text { Feeling of hindrance } \\
\text { Muscle numbness }\end{array}$ & $\begin{array}{l}\text { Intense tiredness in } \\
\text { daily movements } \\
\text { Feeling of drugging } \\
\text { oneself }\end{array}$ \\
\hline \multirow{3}{*}{$\begin{array}{l}\text { INTERPERSONAL } \\
\text { RELATIONSHIP }\end{array}$} & \multirow{2}{*}{$\begin{array}{l}\text { Caregiver-patient } \\
\text { relationship }\end{array}$} & Level of autonomy & Enough Autonomy & $\begin{array}{l}\text { Less autonomy than } \\
\text { in the past }\end{array}$ & Lack of autonomy \\
\hline & & $\begin{array}{l}\text { Type of support } \\
\text { sought }\end{array}$ & Practical support & Motivational support & Emotional support \\
\hline & $\begin{array}{l}\text { Relational } \\
\text { orientation }\end{array}$ & $\begin{array}{l}\text { Openness versus } \\
\text { withdrawal }\end{array}$ & $\begin{array}{c}\text { Relationships seem } \\
\text { unchanged }\end{array}$ & $\begin{array}{l}\text { Relationships have to } \\
\text { be actively sought }\end{array}$ & $\begin{array}{c}\text { Social withdrawal and } \\
\text { loneliness }\end{array}$ \\
\hline
\end{tabular}

Figure 1. Areas of patient's lives affected by fatigue

As for the mind concerns, patients reported alterations in memory, interest and motivation in carrying on everyday activities, and in their emotional status. As for the body concerns, patients generally said that fatigue impacted their sleep quality, sense of hunger, level of energy, and muscle efficiency. Finally, in regards to interpersonal relationships, patients perceived a change in autonomy, in openness to relationships, and in the type of support sought.

\subsection{Changes in Patients' Experiences Based on the Level of Fatigue.}

Patients' fatigue varies basing on the level - mild, moderate and severe - of experienced fatigue (Figure 2).

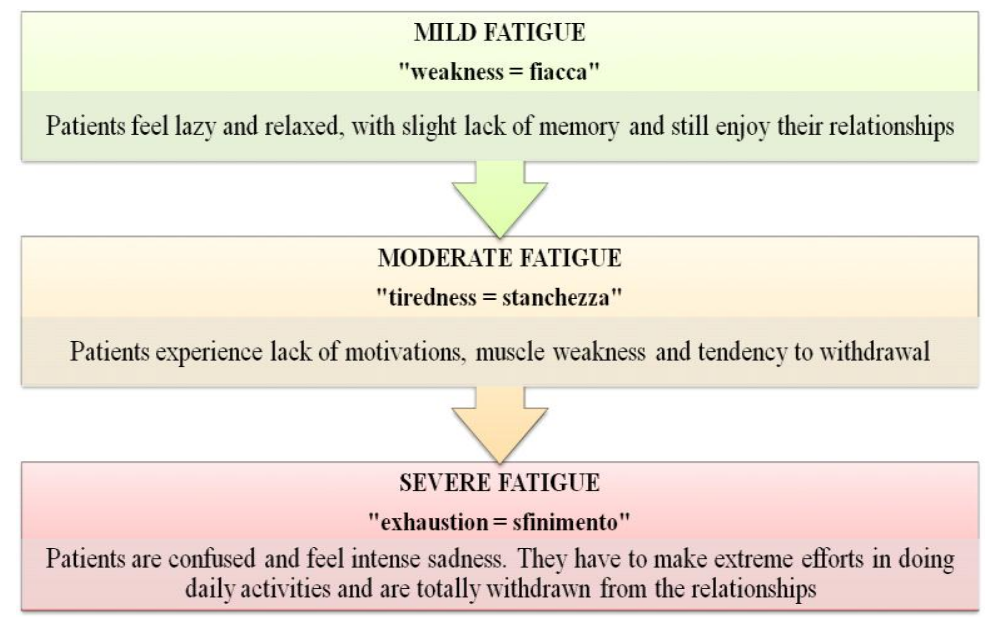

Figure 2. Symptoms experienced across different levels of fatigue

The progressive evolution of fatigue across levels was not clear-cut but can be considered as a continuum. 


\subsubsection{Mild Fatigue}

This level of fatigue was characterized by a general feeling of "weakness" (in Italian "fiacca"). Some patients reported a slight lack of memory associated with a temporary forgetfulness ("I've no more an elephant memory" - Female, 80year old, colon cancer stage III), "a general sense of laziness" (Male, 75year old, colon cancer stage III) and relaxation that one patient described as "to have your mind on holiday." (Male, 59year old, bladder cancer stage IV) Despite this sense of relaxation, some patients reported that they were still able to react. One patient said: "Even if I am a bit tired, I push myself and I pull up" (Male, 75year old, colon-rectal cancer stage III). Sometimes, feelings of anxiety and anger were present. Some patients also described feeling tired after physical efforts and said they needed to "slow down". However they still recovered their energy quickly. Someone reported a sense of sleepiness and described their sleep quality and hunger as normal. Interactions with others did not vary when patients experienced mild fatigue. Patients were generally satisfied with their level of autonomy - "I am alone and I can make it" (Male, 73 year- old, lung cancer stage III) and still enjoy social relationships. One patient stated: "The desire to stay with the others is always present" (Female, 65 year- old, lung cancer stage IV). Some patients appreciated the practical support given by the caregiver/s as it was expressed in these statements: "My husband always take me to medical appointments and help me to understand the information given by the clinicians;" (Female, 71 year- old, breast cancer, stage IV) "My partner helps me to iron, to cook and with the housekeeping." (Female, 65 year- old, lung cancer stage IV).

\subsubsection{Moderate Fatigue}

This level of fatigue was described by a general feeling of "tiredness" (in Italian "stanchezza"). Many patients reported troubles in remembering things - "Memory begins to misfire" (Male, 73 year-old, lung cancer, stage IV) and a sense of boredom characterized by a general lack of stimuli. One patient referred to this sensation as: "There is nothing that thrills me, so I'm bored." (Male, 75 year-old, breast cancer, stage IV). In addition, their mood frequently changed with a swinging between depressive and anxious state:"I have high and low mood." (Female, 75 year-old, stomach cancer, stage IV).

Patients frequently reported disturbed sleep or sleep loss "waking up twice or three times a night" and felt they needed a greater level of energy to cope with daily tasks. They often felt hindered and numb, even in simple movements such as carrying shopping bags or walking. One patient referred to this muscle weakness as "flabby legs." (Male, 75 year-old, colon cancer stage III). Moreover, some patients experienced less desire to eat and reported an altered perception of tastes.

Patients frequently recognized they were less independent - "I can't do everything by myself" (Female, 76 year-old, lung cancer stage IV) and highlighted the importance of a motivational support, beyond a practical help, in order to be encouraged. One patients said: "If I was alone, I can't do anything" (Female, 70-year-old, rectal cancer, stage III). The relational style of these patients was mostly characterized by a tendency to withdrawal. Because of tiredness, social interactions were not spontaneous and had to be actively sought. Some patients described having to push themselves to maintain relationships: e.g. "Sunday, I invited all my sons. Even if I was tired I cooked" (Female, 65 year-old, lung cancer, stage IV).

\subsubsection{Severe Fatigue}

This level of fatigue was described as "exhaustion" (in Italian "sfinimento"). It featured a "collapse" of mind, body and relationships. Mentally, some patients referred to a general sense of confusion and an extreme difficulty to store and recall information: "I feel stunned and I can't remember anything" (Female, 79 year-old, colon cancer, stage III). Due to a generalized feeling of purposelessness, patients reported a lack of motivation and interest in doing any activity. One patients stated: "I don't feel like doing anything and now I give up many things" (Male, 82 year- old, lung cancer, stage IV); "Now I have no more goals." (Male, 73 year- old, lung cancer, stage IV).This condition was commonly associated with intense sadness and "despair."

Physically, patients generally described a total lack of energy "as if the fuel is over" (Female, 79 year- old, colon cancer, stage III) and experienced an extreme effort in doing daily activities even the simplest ones: "To lace up my shoes is fatiguing" (Female, 75 year- old, breast cancer, stage IV). Feeling "drugged" and "feeling breathless" were frequent sensations that hampered activities of daily living. The most of patients described an erratic and not-restoring sleeping, for instance one patients said:"I get up and down from the bed" (Female, 79 year- old, colon cancer, stage III). In the morning they often got up still tired and needed to rest during the day. Hunger was generally absent or really diminished.

In many cases, patients experienced a total lack of autonomy, often associated with "feeling to a be a burden" (Male, 82 year-old, lung cancer, stage IV). In many interviews, patients described their need to be understood 
and psychologically supported by their loved ones. One patient said: "I need someone who could morally support me" (Male, 76 year-old, rectal cancer, stage III). However, extended social relationships were limited and sometimes characterized by loneliness, detachment and withdrawal: "I rather stay in my shell" (Female, 73 year-old, pancreatic cancer, stage IV).

Focusing on the evolution of symptoms across the different levels of fatigue, it may be interesting to highlight that in the "mind" area, patients reported a notable change in their emotional status. In particular, patients experiencing a mild level of fatigue often referred a state of irritability and anxiety, whereas patients with a severe level of fatigue generally reported a significant state of depression and intense sadness.

In regards to the "body" area the level of fatigue seemed to affect the muscles efficiency and the perception of patients' energy availability. Patients with mild fatigue perceived temporary tiredness and a slight muscles weakness; on the contrary, patients with severe fatigue reported a pattern of total loss of energy associated with intense muscles tiredness.

As for the "interpersonal relationships" area, the type of support sought varied shifting from the need for practical support to the need for emotional support.

\subsection{Patients' Explanations of Their Fatigue Experience}

Patients' meaning making processes related to their fatigue were frequent in the interviews and seemed to impact on patients' ability to cope with the disease, both emotionally and behaviorally. As a matter of fact, meanings attributed to the nature and to the causes of fatigue influenced patients' feeling of control over their pathological state and its evolution. Almost all patients reported theories of illness reflecting their subjective causal attribution. In their interviews, we observed that patients showed a differential way of attributing meaning to their experience of fatigue depending on the level of their fatigue (Figure 3).

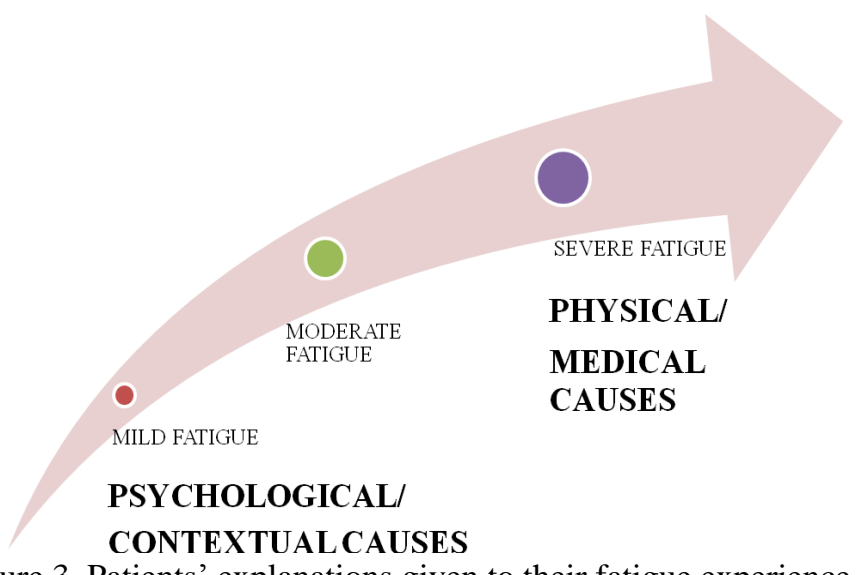

Patients with mild and, to some extent, with moderate fatigue, tended to minimize the gravity of their fatigue and to attribute a psychological/emotional nature to it: "Now I feel a bit tired and lazy, sometimes it happens; I've always had emotional changes" (Male, 59 year old, bladder cancer, stage IV).Furthermore patients were likely to attribute their fatigue to contextual or extrinsic causes, lived as transitory :"I feel week because I have just done chemotherapy" (Female, 50 year old, breast cancer, stage III) ;"I went out yesterday and this makes me tired"(Female, 70 year old, rectal cancer, stage III), and manageable: "I ask too much to myself" (Female, 50 year old, breast cancer, stage III). In some cases, fatigue was meant as a deficit attributable to age, and thus accepted as a "normal" and physiological evolution of life: "I'm old... and this is typical of my age: you lose the strength you had before" (Female, 71 year old, breast cancer, stage IV).

In contrast, patients with a severe level of fatigue seemed to prompt the attribution of physical and more stable causes. These patients often paid a greater attention to fatigue and attributed it to a physical/medical origin. They felt their bodies failed :"My body doesn't work anymore" (Female, 75 year old, stomach cancer, stage IV). This lead patients to perceive their illness status as inexorable and not-manageable. Some patients even described their fatigue as the sign of having reached the final stage of their disease: "I'm completely out of fuel, I'm done" (Female, 79 year old, colon cancer, stage III). It followed a common perception of powerlessness that seemed to impact the psychological endurance of patients of cancer:"I cannot do anything, it is cancer that make me feel like this, it is a symptom of the evolution of my disease" (Male, 82 year old, lung cancer, stage IV). 


\section{Discussion and Conclusions}

The study provided evidences about the complex nature of fatigue. Our data showed that fatigue affects multiple areas of patients' lives, involving physical, psychological and social dimensions although, in the oncology literature, fatigue is often described mostly as a physical symptom thus fostering only interventions aimed at managing and treating its biological manifestations (Bennet et al., 2007; De Raaf et al., 2012). However, the relevance of psycho-social dimensions of fatigue in patients' experience supports the importance of holistic and patient-centred treatment (Stewart et al., 2003). A multidisciplinary management of fatigue, involving all clinicians who take care of the patients' (doctors, nurses, psycho-oncologist, physiotherapists etc.) may results in a process of care and cure that is more aligned with patients' needs. The results of this study suggest that the psychological and social support required by patients may vary depending on their level of fatigue. This study is aligned to the work of others who have suggested that interventions that strengthen the social support network of cancer patients may improve health outcome by protecting them from disease-related stress (Karakoc \& Yurtsever, 2010; House, 2011; Uchino, 2004; Prins et al., 2004).

Another point of interest is the causal attributions that patients give to their fatigue and the way these explanations play a role in shaping patients' behaviours regarding their symptoms. As our data showed, patients' suffering from mild and moderate fatigue attributed their symptoms to external and temporary factors without receiving any information by physicians. Several studies (Gélinas \& Fillion, 2004; Lee, 2008) demonstrated that the ideas that patients have about the causes of fatigue affect their ability to cope with the disease. Furthermore, based on the stress-process theory applied to fatigue (Riedl, 2009), inefficient coping strategies may result in increased fatigue (Laffrey \& Isenberg, 2003). As the literature suggests, patients' ideas about the factors that play a role in controlling their disease reflect their health locus of control which is defined as the perceived control of the individual's own health (Grotz et al., 2011). Patients who attribute the cause of their illness to internal/psychological factors, perceive symptoms to be more under their control. On the contrary attributions to external factors implies a minor perception of control on the disease (Piredda et al., 2007). The results of this study highlight the necessity to deeply consider patients' illness representations and causal assumptions when treating patients. Enhancing patient education interventions regarding the nature and treatment of cancer-related fatigue could enable patients to manage this distressing symptom in a more functional way (Fillion et al., 2008) and adopt more effective coping strategies in order to decrease the impact of fatigue on their lives (Folkman \& Moskowitz, 2000).

Data highlighted the specificity of the Italian dictionary used by patients to describe fatigue. Italian patients shared typical linguistic expressions to describe their experience of fatigue and the specificity of their symptoms' constellations. Linguistic differences in the description of fatigue reveal different perception of the phenomenon. Social constructions of illness experience are mediated through linguistic expressions which are exchanged among people (Radley, 1993). In this sense, the methodology of ethnoscience constituted a powerful approach to explore patients' subjective experience through the analysis of their linguistic expressions and, as a consequence, it can be transferred to other cultural contexts (Graffigna et al., 2011). This method can be also useful to implement cultural based interventions. Working with linguistic representations of illness and symptoms contributed to the creation of a shared "dictionary" that patients referred to when describing their fatigue. This dictionary may be a useful tool for clinicians to provide information about fatigue and may offer a pragmatic insight for better orienting care and cure interventions for cancer-related fatigue (Barsevick et al., 2001). In addition, using this situated language might improve patients' understanding and the relationship between patients and health-care professionals thus fostering patient engagement in their care process which is widely recognized as an important factor in gaining better health outcomes (Barello et al., 2012). It is possible that, when clinicians share a common language, patients feel better understood and supported, thus improving their quality of life.

A further challenge suggested by our results is that, despite its high prevalence and its strong impact on patients' quality of life (Bower et al., 2000) the relevance of fatigue is often underestimated by clinicians and, as a consequence, the education about fatigue is not always seen as a priority (Laugsand et al., 2010). In addition, while diagnosis and treatment research have increased the hope of survival and even cure for many cancer patients, not so much attention has been paid to improve patients' everyday quality of life. Further research could study the effects of interventions based on local beliefs and values in order to manage fatigue and improve patients' well-being.

A growing number of authors from various countries have focused on fatigue but they did not address the nature of fatigue may vary across cultures; this study has explored the social construction of fatigue in Italian cancer patients and a further challenge will be to compare the data obtained among the five countries of the Fatigue 
Study Project and develop a cross-cultural understanding of fatigue. A preliminary comparison of the cross-cultural results can be find in the paper by Kirshbaum et al. (2010) where preliminary analysis showed that while both "body" and "mind" are central to the nature of fatigue in all four study populations, the dimensions within these two central domains vary thus stimulating discussion surrounding the ways culture shapes the meaning of illness and therefore influence directions toward culturally sensitive interventions. Our results provides further evidences that symptom and illness experience are socially constructed thus suggesting the need to consider that in order to develop effective and tailored interventions. From this perspective, ethnoscience provides a systematic research approach but, due its flexibility, it can be easily adapted to the local research practices and cultural context in which data are collected. This methodology allowed to highlight the pivotal features of the phenomenon under investigation valuing cultural and social issues.

The present study has some limitations. The first is related to the methodology and in particular to the card-sort task. For some patients this task was hard to complete due to the high level of abstract thinking required. As a consequence, some patients were less articulate in explaining their reasoning behind their card sort. Secondly, as the study design involved several steps and a strong commitment on the part of patients, the study population resulted to be "self-selected". Finally, our results foster a reflection upon the importance of considering the methodological challenges related to research into the experiential and interpersonal aspects of care \& cure processes. Developing such knowledge and understanding the relevance of bottom-up qualitative methodological approaches, such as ethnoscience, able to value patient's subjective experience could contribute to a better interpretation of obtained results thus developing better tailored clinical interventions able to value patients' believes and maximize their cultural and social identity. This methodology could also contribute to easier find out emerging or silent health care needs that are useful to re-orient health policies really able to sustain a higher and effective patient engagement in healthcare.

\section{References}

Aistars, J. (1987). Fatigue in the cancer patient: a conceptual approach to a clinical problem. Oncology Nursing Forum, 14, 25-30. http://dx.doi.org/10.1002/cncr.25681

Baider, L., \& Surbone, A. (2010). Cancer and the family: the silent words of truth. Journal of Clinical Oncology, 28, 1269-1272. http://dx.doi.org/10.1200/JCO.2009.25.1223

Barello, S., Graffigna, G., \& Vegni, E. (2012). Patient engagement as an emerging challenge for healthcare services: mapping the literature. Nursing Research and Practice. 2012:905934. http://dx.doi.org/10.1155/2012/905934.

Barsevick, A., Newhall, T., \& Brown, S. (2008). Management of Cancer-Related Fatigue. Clinical Journal of Oncology Nursing, 12, 21-25.

Barsevick, A., Whitmer, K., \& Walker, L. (2001). In their own words: using the common sense model to analyze patients descriptions of cancer-related fatigue. Oncology Nursing Forum, 28, 1363-1369.

Bennett, B., Goldstein, D., Friedlander, M., Hickie, I., \& Lloyd, A. (2007). The experience of cancer-related fatigue and chronic fatigue syndrome: a qualitative and comparative study. Journal of Pain and Symptom Management, 34, 126-35. http://dx.doi.org/10.1016/j.jpainsymman.2006.10.014

Bower, J. E., Ganz, P. A., Desmond, K. A., Rowland, J. H., Meyerwitz, B. E., \& Berlin, T. R. (2000). Fatigue in breast cancer survivors: occurrence, correlates and impact on quality of life. Journal of Clinical Oncology, $18,743-753$.

Broeckel, J. A., Jacobsen, P. B., Horton, J., Balducci, L., \& Lyman, G. H. (1998). Characteristics and correlates of fatigue after adjuvant chemotherapy for breast cancer. Journal of Clinical Oncology, 16, 1689-96. http://dx.doi.org/10.1016/S0885-3924(99)00082-2

Bruera, E., Kuehn, N., Miller, M. J., et al. (1991). The Edmonton Symptom Assessment System (ESAS): a simple method for assessment of palliative care patients. Journal of Palliative Care, 7, 6-9.

Buchwald, D., Pearlman, T., Umanli. J., Schmaling, K., \& Katon, W. (1996). Functional status in patients with chronic fatigue syndrome (CFS) and fibromyalgia. Social Science \& Medicine, 54, 711-720.

Centeno, E., Portela Tejedor, M. A., Carvajal, A., San Miguel, M. T., Urdiroz, J., Ramos, L., et al. (2009). What is the best term in Spanish to express the concept of cancer-related fatigue? Journal of Palliative Medicine, $12,441-445$.

Charles, C., Gafni, A., Whelan, T., \& O’Brien, M. A. (2006). Cultural influences on the physician-patient encounter: The case of shared treatment decision-making. Patient Education and Counseling, 63, 262-7. 
http://dx.doi.org/10.1016/j.pec.2006.06.018

Chow, E., Abdolell, A., Panzarella, T., et al. (2008). Predictive model for survival in patients with advanced cancer. Journal of Clinical Orthodontics, 26, 5863-5869.

Costantini, M., Marasso, G., Montella, M., et al. (2006). Diagnosis and prognosis disclosure among cancer patients. Results from an Italian mortality follow-back survey. Annals of Oncology, 17, 853-859. http://dx.doi.org/10.1093/annonc/mdl028

De Raaf, P. J., Sleijfer, S., Lamers, C. H. J., Jager, A., Gratama, J. W., \& Van Der Rijt, C. C. D. (2012). Inflammation and fatigue dimensions in advanced cancer patients and cancer survivors: An explorative study. Cancer, 118, 6005-6011. http://dx.doi.org/10.1002/cncr.27613

David, A., Pelosi, A., Mc Donald, E., Stephens, D., Ledger, D., Rathbone, R., et al. (1990). Tired, weak, or in need of rest: fatigue among general practice attenders. British Medical Journal, 301, 1199-1202.

Di Mola, G., \& Crisci, M. T. (2001). Attitudes towards death and dying in a representative sample the Italian population. Palliative Medicine, 15, 14372-14378. http://dx.doi.org/10.1191/026921601680419410

Donovan, K. A., Mcginty, H. L., \& Jacobsen, P. B. (2012). A systematic review of research using the diagnostic criteria for cancer-related fatigue. Psycho-Oncology (in press).

Fillion, L., Gagnon, P., Leblond, F., Gélinas, C., Savard, J., Dupuis, R., Duval, K., \& Larochelle, M. (2008). A brief intervention for fatigue management in breast cancer survivors. Cancer Nursing, 31, 45-59. http://dx.doi.org/10.1097/01.NCC.0000305698.97625.95

Folkman, S., \& Moskowitz, J. T. (2000). Positive affect and the other side of coping. The American Psychologist, 55, 647-654. http://dx.doi.org/10.1037//0003-066X.55.6.647

Forlenza, M. J., Hall, P., Lichtenstein, P., Evengard, B., \& Sullivan, P. F. (2005). Epidemiology of cancer-related fatigue in the Swedish twin registry. Cancer, 104, 2022-2031. http://dx.doi.org/10.1002/cncr.21373

Gélinas, C., \& Fillion, L. (2004). Factors related to persistent fatigue following completion of breast cancer treatment. Oncology Nursing Forum, 31, 269-277. http://dx.doi.org/10.1188/04.ONF.269-278

Glaus, A. (1998). Fatigue in patients with cancer: analysis and assessment. Berlin: Springer.

Graffigna, G., Vegni, E., Barello, S., Olson, K., \& Bosio, C.A. (2011). Studying the social construction of cancer-related fatigue experience: the heuristic value of Ethnoscience. Patient Education and Counseling, 82, 402-9. http://dx.doi.org/10.1016/j.pec.2010.12.017

Grotz, M., Hapke, U., Lampert, T., \& Baumeister, H. (2011). Health locus of control and health behavior: results from a nationally representative survey. Psychology, Health \& Medicine, 16, 129-40. http://dx.doi.org/10.1080/13548506.2010.521570

House, J. S. (2001). Social isolation kills, but how and why? Psychosomatic Medicine, 63(2), 273-274.

Kaissi, A., Kralewski, J., Curoe, A., Dowd, B., \& Silversmith, J. (2004). How does the culture of medical group practices influence the types of programs used to assure quality of care? Health Care Management Review, $29,129-38$.

Karakoç, T., \& Yurtsever, S. (2010). Relationship between social support and fatigue in geriatric patients receiving outpatient chemotherapy. European Journal of Oncology Nursing, 14, 61-7. http://dx.doi.org/10.1016/j.ejon.2009.07.001

Kirshbaum, N., Olson, K., Graffigna, G., \& Pongathavornkamol, K. (2010). An ethnoscience approach to develop a cross-cultural understanding of fatigue. Current Oncology, 17, 247. http://dx.doi.org/10.1016/j.ejon.2012.04.007

Kirshbaum, M. N., Olson, K., Pongthavornkamol, K., \& Graffigna, G. (2012). Understanding the meaning of fatigue at the end of life: An ethnoscience approach. European Journal of Oncology Nursing, [Epub ahead of print]

Krupp, L. B., Alvarez, L. A., LaRocca, N. G., Scheinberg, L. C. (1988). Fatigue in multiple sclerosis. Archives of Neurology, 45, 435-437.

Laffrey, S. C., \& Isenberg, M. (2003). The relationship of internal locus of control, value placed on health, perceived importance of exercise, and participation in physical activity during leisure. International Journal of Nursing Studies, 40, 453-459. http://dx.doi.org/10.1016/S0020-7489(03)00061-0 
Laugsand, E. A., Sprangers, M. A., Bjordal, K., Skorpen, F., Kaasa, S., \& Klepstad, P. (2010). Health care providers underestimate symptom intensities of cancer patients: a multicenter European study. Health and Quality of Life Outcomes, 21, 104. http://dx.doi.org/10.1186/1477-7525-8-104

Lee, V. (2008). The existential plight of cancer: meaning making as a concrete approach to the intangible search for meaning. Supportive Care in Cancer, 16, 779-785. http://dx.doi.org/10.1007/s00520-007-0396-7

Leventhal, H., Benyamini, Y., Brownlee, S., et al. (1997). Illness representations: theoretical foundations. In: Petrie, K.J., Weinman, J. (eds). Perceptions of health and illness (pp. 155-88)Amsterdam: Harwood Academic.

Mock, V., Atkinson, P., Barsevick, A., et al. (2007). Cancer-related fatigue. Clinical practice guidelines in oncology. Journal of National Comprehensive Cancer Network, 5, 1054-1078.

Moore, T., Norman, P., Harris, P. R., \& Makris, M. (2008). An interpretative phenomenological analysis of adaptation to recurrent venous thrombosis and heritable thrombophilia: the importance of multi-casual models and perceptions of primary and secondary control. Journal of Health Psychology, 13, 776-84.

Nail, L. M. (2002). Fatigue in patients with cancer. Oncology Nursing Forum, 29, 537-544. http://dx.doi.org/10.1188/ONF.537-546

Olson, K. (2007). A new way of thinking about fatigue: a reconceptualization. Oncology Nursing Forum, 34, 93-99. http://dx.doi.org/10.1188/07.ONF.93-99

Olson, K., Krawchuck, A., \& Quddusi, T. (2007). Fatigue in individuals with advanced cancer in active treatment and palliative settings. Cancer Nursing, 30, E1-E10. http://dx.doi.org/10.1097/01.NCC.0000281736.25609.74

Orre, I. J., Reinertsen, K. V., Aukrust, P., Dahl, A. A., Fosså, S. D., Ueland, T., \& Murison, R. (2011). Higher levels of fatigue are associated with higher CRP levels in disease-free breast cancer survivors. Journal of Psychosomatic Research, 71, 136-141. http://dx.doi.org/10.1016/j.jpsychores.2011.04.003

Piredda, M, De Marinis, M. G., Rocci, L. et al. (2007). Meeting information need on cancer-related fatigue: an exploration of views held by Italian patients and nurses. Supportive Care in Cancer, 15, 1231-1241. http://dx.doi.org/10.1007/s00520-007-0240-0

Prins, J. B., Bos, E., Huibers, M. J. H., Servaes, P., Van Der Werf, S. P., Van Der Meer, J. W. M., \& Bleijenberg, G. (2004). Social support and the persistence of complaints in chronic fatigue syndrome. Psychotherapy and Psychosomatics, 73, 174-182. http://dx.doi.org/10.1159/000076455

Rakib, A., Pinching, A. J., Priebe, S., \& White, P. D. (2005). Subjective quality of life in patients with chronic fatigue syndrome. Quality of Life Research, 14, 11-19. http://dx.doi.org/10.1007/s11136-004-1693-y

Radley, A. (1993). Worlds of Illness: Biographical and Cultural Perspectives on Health and Illness. London : Routledge.

Richards, L., \& Morse, J. (2007). Readme First for a User's Guide to Qualitative Methods. London: Sage Publication.

Riedl, A., Maass, J., Fliege, H., Stengel, A., Schmidmann, M., Klapp, B. F., \& Mönnikes, H. (2009). Subjective theories of illness and clinical and psychological outcomes in patients with irritable bowel syndrome. Journal of Psychosomatic Research, 67, 449-445. http://dx.doi.org/10.1016/j.jpsychores.2009.02.001

Sakauye, K. M. (2005). Cultural influences on pain management in the elderly. Comprehensive Therapy, 31, 78-82. http://dx.doi.org/10.1385/COMP:31:1:078

Servaes, P., Verhagen, C., \& Bleijenberg, G. (2002). Fatigue in cancer patients during and after treatment: prevalence, correlates and interventions. European Journal of Cancer, 38, 27-43. http://dx.doi.org/10.1016/S0959-8049(01)00332-X

Schoofs, N., Bambini, D., Ronning, P., Bielak, E., \& Woehl, J. (2004). Death of a lifestyle: The effects of social support and healthcare support on the quality of life of persons with fibromyalgia and/or chronic fatigue syndrome. Orthopaedic Nursing, 23, 364-374. http://dx.doi.org/10.1097/00006416-200411000-00005

Solano, J. P., Gomes, B., \& Higginson, I. J. (2006). A comparison of symptom prevalence in far advanced cancer, AIDS, heart disease, chronic obstructive pulmonary disease and renal disease. Journal of Pain and Symptom Management, 31, 58-69. http://dx.doi.org/10.1016/j.jpainsymman.2005.06.007

Spradley, J. P. (1979). The ethnographic interview. New York: Rinehart \& Winston 
Stewart, M., Brown, J., Weston, W. W., McWhinney, I. R., McWilliam, C. L., \& Freeman, T. R. (2003). Patient-centred medicine. Transforming the clinical method. Oxon: Radcliff Medical Press.

Surbone, A., Ritossa, C., \& Spagnolo, A. G. (2004). Evolution of truth-telling attitudes and practices in Italy. Critical Review of Oncology/Hematology, 52, 165-172. http://dx.doi.org/10.1016/j.critrevonc.2004.10.003

Uchino, B. N. (2004). Social support and physical health: Understanding the health consequences of relationships. New Haven: Yale University Press.

Wolfe, F., Hawley, D. J., \& Wilson, K. (1996). The prevalence and meaning of fatigue in rheumatic disease. The Journal of Rheumatology, 23, 1407-1417.

\section{(cc) EY}

This work is licensed under a Creative Commons Attribution 3.0 License. 